\title{
Parameters of the Azov-Black Sea Region Precipitation Based on the Model and Observational Data
}

\author{
D.A. Iarovaia*, V.L. Pososhkov \\ Marine Hydrophysical Institute, Russian Academy of Sciences, Sevastopol, Russian Federation \\ *e-mail: daryk777@inbox.ru
}

\begin{abstract}
The results of precipitation simulation in the Azov-Black Sea region are verified using the observational data from the meteorological stations of the North Eurasia Climate Centre. In particular, the results of global (MERRA) and regional (PRECIS and RegCM) reanalyses are considered. Verification is done in accordance to two criteria: "index of agreement" and "probability of detection". Reliability of the precipitation basic parameters (intensity and frequency) is assessed; the modeled and the measured distribution functions of daily precipitation are compared. It is shown that in all the reanalyses the results of the winter precipitation modeling are in better agreement with the observational data than those resulted from the summer precipitation modeling. In summer, according to certain parameters, the regional reanalyses are in better agreement with the observational data than the global reanalysis. Particular attention is paid to the data obtained at the meteorological station located in the region of complex orography and intensive precipitation (Sochi). It is shown that the winter precipitation in Sochi derived from the regional reanalyses is significantly overestimated, especially as for the extreme precipitation.
\end{abstract}

Keywords: precipitation reanalysis, precipitation in the Azov-Black Sea region, reanalysis verification, regional modeling, distribution function

DOI: 10.22449/1573-160X-2017-1-11-24

(C) 2017, D.A. Iarovaia, V.L. Pososhkov

(C) 2017, Physical Oceanography

\section{Introduction}

Numerical modeling of precipitation is of great practical importance and is widely used in solving such research-applied problems as a forecasting of flush floods, mudflows and floods. Global atmospheric circulation models with the assimilation of observational data (from meteorological stations and satellites) are used for obtaining precipitation climatic fields, as well as other meteorological characteristics. However, due to low spatial resolution these models are not suitable for studying local climatic processes. Regional models allow one to recalculate global modeling results in the limited area to a finer grid with up to several tens of kilometers resolution. Unfortunately, precipitation modeling results not always get better at that. For instance, in $[1,2]$ it is found out that mean monthly amount of winter precipitation in the northern part of Azov-Black Sea region is significantly overestimated in the $\operatorname{Reg} C M$ regional model [3] (in comparison with the observational data). In the MERRA reanalysis [4], obtained by the global model, such discrepancies were not observed. This is related to the fact that precipitation calculation schemes in regional models usually require adaptation to each specific region. In [2], after a number of numerical experiments the values of empirical coefficients, which were most suitable for the RegCM model when reconstructing the Azov-Black Sea region precipitation, were determined.

It is of interest to compare global and regional models by the accuracy of climatic precipitation field reproduction in the Azov-Black Sea region. In this 
paper, two regional reanalyses (PRECIS and RegCM) and MERRA reanalysis (obtained by the global model) are considered to identify the main discrepancies between the data of reanalysis and field observations using various quantitative criteria, such as "index of agreement" and "probability of detection".

This study is a continuation of a series of papers $[1,2,5]$. In the first of them $\operatorname{RegCM}$ regional reanalysis was compared with the MERRA [4] and ERA-Interim [6] global reanalyses for 1979 - 2013 [1]. In the second paper it was drawn a conclusion that for the considered period of $1980-2013$ in the northern part of the Azov-Black Sea region total mean monthly precipitation amount in $\operatorname{Reg} C M$ model (in comparison with observational data (ECA\&D, E-OBS, and $N C D C$ datasets) and the MERRA, ERA-Interim global reanalyses) was underestimated in summer and significantly overestimated in winter [2]. In [5], the verification of precipitation modeling results by the PRECIS regional model was carried out for relatively short 2000 - 2006 period using the satellite data and measurement data from the meteorological stations.

In the above-mentioned studies the verification was carried out either for short period [5] or using the results of global reanalysis as a control dataset [1]. In $[1,2]$, when assessing the modeling results, space-averaged mean monthly rainfall, precipitation intensity and frequency were considered. In the given research verification was carried out for a longer period than in [5], and there were compared two regional models, not one as in $[1,2]$.

Significant advantage of the given study is the fact that during the verification a small time scale (equal to one day) was used. It is known that if averaging is performed on large time scales when comparing simulation results with observational data, this masks the imperfection of the model and smoothens the discrepancy between the model and observational data.

In recent times most countries apply categorical verification scheme using contingency tables and calculation of a set of assessments recommended by the World Meteorological Organization (WMO), or are about to shift to it. Thus, this was the topic of the $6^{\text {th }}$ WMO Verification Methods Workshop that took place in India (Delhi) on March 13 - 19, 2014. Therefore, in this research, in addition to the "index of agreement" numerical criterion applied in [5], the "probability of detection" categorical criterion (which is one of assessment characteristics of the standardized verification system adopted by WMO [7]) is used.

\section{Description of the data}

The following datasets were applied in the study:

- A dataset of North Eurasia Climate Center (NEACC) [8], containing the data of field observations from 223 meteorological stations located in the territory of CIS. Time series related to different meteorological stations cover different periods, but they all end in 2006. Further the NEACC dataset will be used for verification of the MERRA, PRECIS and RegCM reanalyses. In the Annex 1 the names and geographical coordinates of 24 meteorological stations situated in the Azov-Black Sea region $\left(39-50^{\circ} \mathrm{N}, 25-45^{\circ} \mathrm{E}\right)$ are listed, and relative number of days missed over the considered period is given. Although the proportion of missed days at some meteorological stations reaches $50 \%$, the NEACC dataset is preferable to the $E C A \& D$ one [9], which was used for verification in our previous study [2]. 
There are less missed days in $E C A \& D$, but daily precipitation amount in certain days is incredibly high. Unreliable values were rejected from the NEACC dataset.

- Regional reanalyses the PRECIS [10] with $0.22^{\circ}$ resolution for $1990-2007$ and $\operatorname{RegCM}$ with $25 \mathrm{~km}$ resolution for 1979 - 2013. In both regional reanalyses initial and boundary conditions were specified from the global the ERA-Interim reanalysis during the modeling.

- the MERRA reanalysis, which is a result of global modeling with satellite data and contact observation data assimilation. Its spatial resolution is $1 / 2 \times 2 / 3^{\circ}$ and it covers the period from 1979 to the present time. Its resolution $(\sim 40 \times 70 \mathrm{~km})$ is lower than in regional reanalyses but the MERRA forecast system has an additional factor that improves the quality of the modeling: the assimilation of cumulus clouds satellite observations.

For the NEACC dataset, as well as for the MERRA and RegCM reanalyses, all the characteristics were calculated over 1980 - 2006, and for the PRECIS reanalysis - over 1990 - 2006.

\section{Verification methods and precipitation characteristics}

Verification of models was carried out using different numerical measures calculated by the observational data (obtained at meteorological stations) and on the basis of model data in the closest grid node. As grid nodes do not coincide with positions of meteorological stations, this leads to certain errors in assessment criteria calculation. Different methods of interpolation are used for overcoming these difficulties. However, due to the extremely high spatial variability of the precipitation field (particularly of shower-type precipitation) such methods are unproductive. Another way to solve this problem consists in improving the spatial resolution of climate models. As mentioned above, resolution of regional models reaches $25 \mathrm{~km}$ in this study. This fact reduces the discrepancy between the coordinates of meteorological station under consideration and the nearest grid node. It is clear that this does not completely eliminate the error in assessment criteria, but it is difficult to propose an alternative.

When verifying the reanalyses, such values as precipitation intensity $\left(p r_{\text {ave }}\right)$ and frequency (freq) were calculated. Precipitation intensity means daily average precipitation amount on wet days. Frequency is defined as a ratio of number of wet days to the total number of the days. The day is considered to be rainy if the daily precipitation amount $p r$ exceeds the threshold value $p r_{\text {min. }}$. The selection of $p r_{\text {min }}$ value plays an important role in frequency calculation due to the fact that small $\mathrm{pr}$ values are not recorded at meteorological stations and even small daily precipitation amount are reproduced in the models. This can significantly increase the number of wet days. In [5] it is revealed that the most suitable $p r_{\text {min }}$ value for the Azov-Black Sea region is $1 \mathrm{~mm}$. Therefore, during the calculation of $p r_{\text {ave }}$ and freq only those days when daily precipitation amount exceeded $1 \mathrm{~mm}$ were taken into account.

To assess how successfully reanalysis predicted the presence of precipitation, "probability of detection" criterion (POD) [11] was applied. It is determined by the formula

$$
P O D=N_{11} / N,
$$


where $N_{11}$ is a number of days when precipitation took place both by reanalysis data and observational data; $N$ is total amount of days over the period under consideration. The range of $P O D$ value variation is from 0 to 1 (in case of an ideal forecast).

To assess the forecast quality, "index of agreement" criterion $(d)$ is used:

$$
d=1-\frac{\sum_{i=1}^{N}\left(P_{i}^{\prime}-O_{i}^{\prime}\right)^{2}}{\sum_{i=1}^{N}\left(\left|P_{i}^{\prime}\right|+\left|O_{i}^{\prime}\right|\right)^{2}},
$$

where $O_{i}$ is the observed value; $P_{i}$ is the forecasted value; $P_{i}^{\prime}=P_{i}-\bar{O}, O_{i}^{\prime}=O_{i}-\bar{O}$ are the deviations from the observed mean [12]. In our case $O_{i}$ is daily precipitation amount registered on the $i^{\text {th }}$ day at the considered meteorological station, and $P_{i}$ is reanalysis data for the same day at the closest computational grid node. It is necessary to emphasize that $P_{i}^{\prime}$ is a forecasted value deviation from the average observed value, not from the average forecasted one. $d$ value varies within $[0 ; 1]$ range of values ( 1 means an ideal forecast when $\left.P_{i}=O_{i}\right)$. In fact, formula (2) is an expression $d=1-\frac{\sigma^{2}}{\sigma_{\max }^{2}}$ where $\sigma$ is root-mean-square error defined as $\sigma^{2}=\frac{1}{N} \sum_{i=1}^{N}\left(P_{i}^{\prime}-O_{i}^{\prime}\right)^{2}$. From the latter expression it is obvious that $\sigma^{2}$ reaches its maximum value when $P_{i}^{\prime}$ and $O_{i}^{\prime}$ deviations are in anti-phase, i.e. $P_{i}^{\prime}=-\alpha \cdot O_{i}^{\prime}$, where $\alpha$ is an arbitrary positive number. In this case $d$ is equal to 0 .

Like frequency, the index of agreement depends on $p r_{\min }$, but this dependence is weak. With an increase of $p r_{\min }$ by an order of magnitude, from 0.1 to $1 \mathrm{~mm}$, the frequency averaged over the stations decrease by $30-80 \%$, and the index of agreement - only by $2-9 \%$. Further, when calculating $d$ (and also $\bar{O}$ with respect to which $P_{i}^{\prime}$ and $O_{i}^{\prime}$ were calculated) only those days in which the values of both $O_{i}$, and $P_{i}$ were greater than $p r_{\text {min }}$ (equal to $1 \mathrm{~mm}$ ) were taken into account.

In the present paper the distribution functions of daily precipitation amount were also considered. It is known that cumulative distribution function of precipitation amount can be described by gamma distribution with a high degree of accuracy:

$$
F(p r)=\int_{-\infty}^{p r} \frac{(x \cdot \beta)^{\alpha-1} e^{-x \cdot \beta}}{\beta \cdot \Gamma(\alpha)} d x
$$

where $p r$ is daily precipitation amount in wet days; $\Gamma(\alpha)$ is a gamma function which is equal by a definition to $\Gamma(\alpha)=\int e^{-t} t^{\alpha-1} d t, \alpha$ is called a shape parameter, $\beta-$ a scale parameter. To assess $\alpha$ and $\beta$ gamma distribution parameters, a method of moments [13] was applied.

In addition to the theoretical distribution function determined by expression (3), we constructed the statistical distribution function

$$
F^{*}(p r)=N_{p r} / N
$$


where $N_{p r}$ is a number of days in which precipitation amount was less than $p r$. As the expression (3) describes the distribution of a random variable, which is strictly positive (i.e. it can not take the value equal to zero), only the days when the precipitation fell were considered in calculating the statistical function $F^{*}(p r)$. When constructing the distribution function $F^{*}(p r), 0.1 \mathrm{~mm}$ interval was selected (the maximum resolution of the rain gauge).

\section{Results and discussion}

The intensity of winter and summer precipitation at different meteorological stations is given in Fig. 1. In winter relative error in $p r_{\text {ave }}$ calculation at certain meteorological stations can reach $50 \%$ but in general the data of the reanalyses corresponds well with the observational data. Relative error averaged over all stations makes up 10, 15 and $20 \%$ for the RegCM, PRECIS and MERRA reanalyses, respectively. At most meteorological stations $p r_{\text {ave }}$ is underestimated. In summer precipitation intensity at almost all meteorological stations is underestimated by $30-45 \%$, and the coefficients of correlation between $p r_{a v e}$ and the relative error make up $0.7-0.8$, i.e. the larger is the measured summer precipitation intensity, the greater is the relative underestimation of this value in the reanalyses.

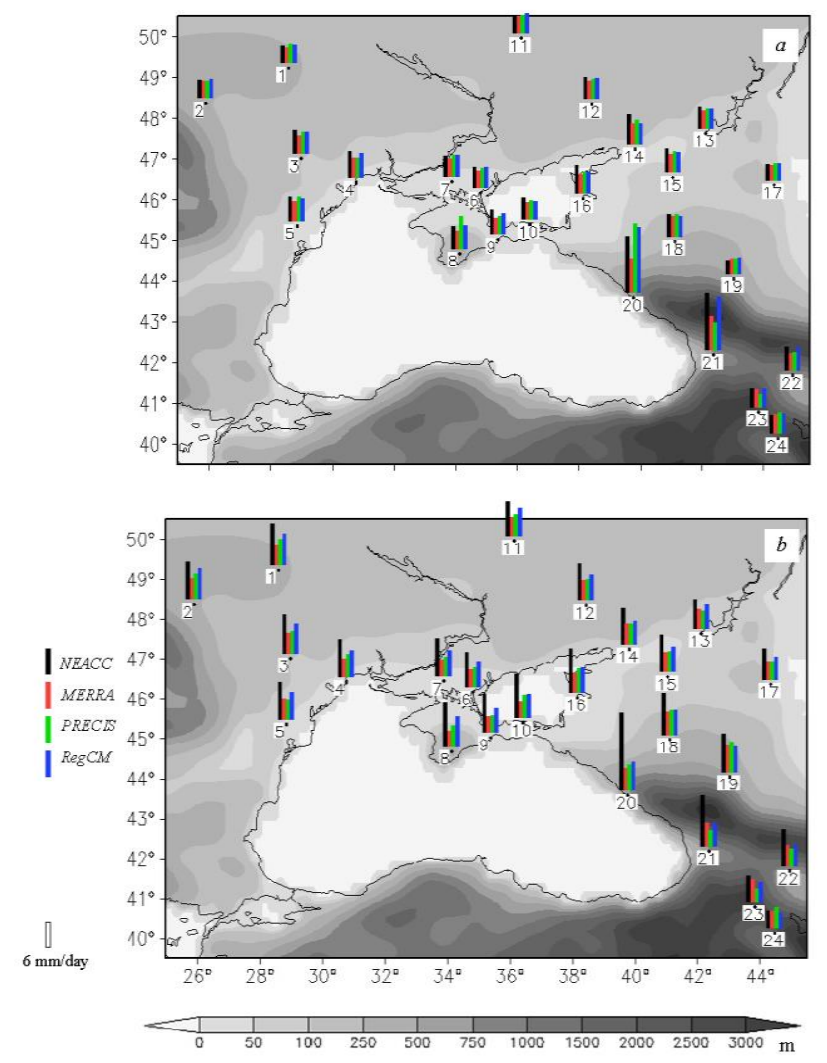

Fig. 1. Precipitation intensity prave $(\mathrm{mm})$ in winter $(a)$ and in summer $(b)$. Terrain height above the sea level $(\mathrm{m})$ is denoted by the shades of grey 
It should also be noted that according to [2], in the northern part of the AzovBlack Sea region $\left(24-48^{\circ} \mathrm{E}, 47-54^{\circ} \mathrm{N}\right)$ space-averaged precipitation intensity in the $\operatorname{RegCM}$ reanalysis is overestimated in comparison with the MERRA. This is confirmed by Fig. 1: at all the stations situated to the north of $47^{\circ} \mathrm{N} p r_{\text {ave }}$ values are greater in the $\operatorname{RegCM}$ reanalysis than in the MERRA one.

Precipitation frequency is overestimated in all the reanalyses, especially in summer (Fig. 2). In winter the MERRA reanalysis is the best in forecasting the presence of precipitation, the RegCM one is the worst. For the summer precipitation the opposite situation is observed: precipitation frequency calculated by $\operatorname{Reg} C M$ is the best in corresponding with the observational data and the frequency calculated by MERRA is the worst. This is consistent with the conclusion drawn in [2]: in the northern part of Azov-Black Sea region winter precipitation frequency in the $\operatorname{Reg} C M$ reanalysis is overestimated (in comparison with the $M E R R A$ ) and summer precipitation frequency is underestimated. As it was mentioned above, precipitation frequency and probability of detection strongly depend on $p r_{\min }$ threshold value for the determination of wet days. However, if to double $p r_{\min }$ threshold value from 1 to $2 \mathrm{~mm}$, the conclusion on the fact that precipitation frequency in the reanalyses is overestimated will not change.
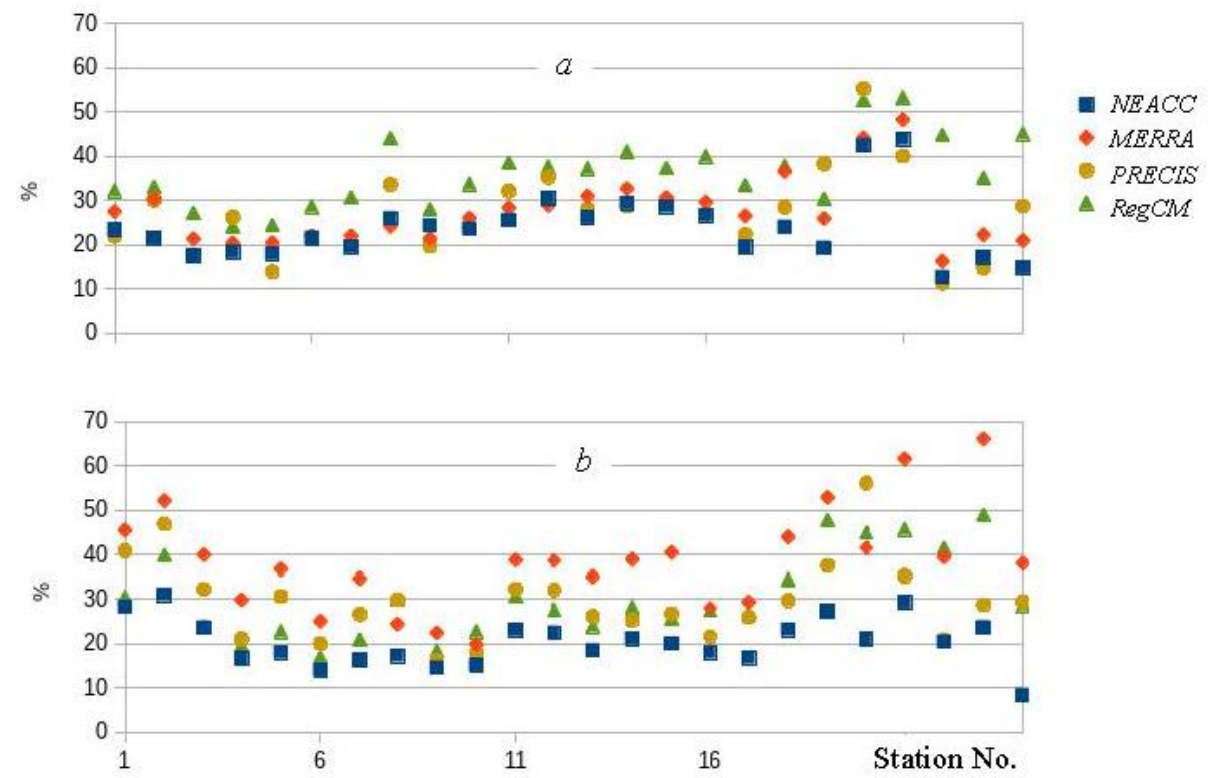

Fig. 2. Precipitation frequency freq $(\%)$ at the stations in winter $(a)$ and in summer $(b)$

Now we are to consider total amount of precipitation, which is equal to the product of intensity by the frequency ( $p r_{\text {ave }}$ freq). Here the following discrepancies between the reanalysis data and observational one are revealed:

- In the $\operatorname{Reg} C M$ reanalysis total amount of winter precipitation is highly overestimated at almost all the meteorological stations. This is consistent with the conclusions of $[1,2]$. According to [1], overestimation of $p_{\text {ave }}$ freq is mainly 
related to the overestimation of precipitation intensity. But it should be pointed out that in [1] the data of the ERA-Interim global reanalysis was applied for the $\operatorname{RegCM}$ regional reanalysis verification. If the data of contact observations is used for verification (as in the given study), it turns out that overestimation of $p r_{\text {ave }} \cdot$ freq is due to the frequency overestimation (Fig. 2, $a$ ).

- In the PRECIS reanalysis total amount of summer precipitation is generally underestimated which is related to underestimation of its intensity.

In other cases total precipitation amount averaged over the stations corresponds with observational data well.

The main conclusion is the following: in all the reanalyses, when reconstructing the summer convective precipitation, the amount of wet days (when $p r>1 \mathrm{~mm}$ ) is, in general, more than according to the measurement data, and the daily average amount of precipitation falling in these days is less, i.e. the reproduction of summer precipitation needs to be improved.

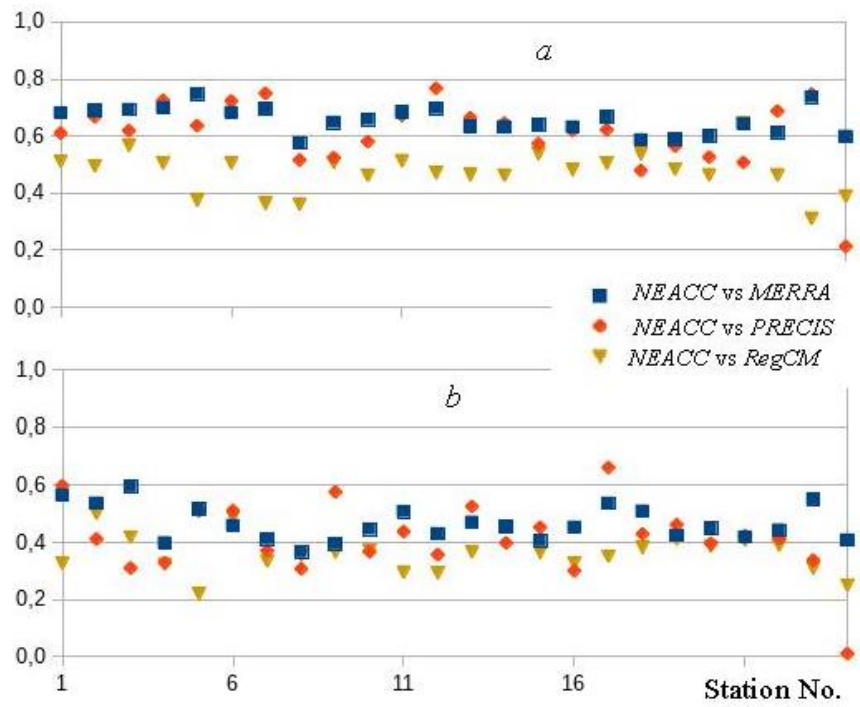

Fig. 3. Index of agreement in winter $(a)$ and in summer $(b)$

It is obvious from Fig. 3 that according to "index of agreement" criterion in all the reanalyses winter precipitation is forecasted better than the summer one. In winter the value $d$ (averaged over the stations) makes up 0.66 for the MERRA reanalysis, 0.61 for the PRECIS and 0.47 for the RegCM reanalysis; in summer $0.47,0.41$ and 0.36 for the MERRA, PRECIS and RegCM reanalysis, respectively. The global reanalysis forecasts precipitation better than the regional ones: at the vast majority of meteorological stations index of agreement in MERRA is higher than in the PRECIS and RegCM. It should be pointed out that in winter index of agreement in the $\operatorname{Reg} C M$ reanalysis is noticeably smaller than in MERRA and PRECIS (Fig. 3, a). Apparently, this can be explained by the fact that, as mentioned above, the frequency of winter precipitation in $\operatorname{Reg} C M$ (Fig. 2,a) is overestimated. As a result, the predicted mean and the observed mean significantly 
differ. All the foregoing can be illustrated by presenting the root-mean-square error in $\sigma^{2}=D_{P}+D_{O}-2 K_{P O}+(\bar{P}-\bar{O})^{2}$ form, where $D_{P}$ and $D_{O}$ are dispersions of $P_{i}$ and $O_{i} ; K_{P O}$ is a covariance of $P_{i}$ and $O_{i} ; \bar{P}$ is the mean of the model-predicted variable.

Now we are to consider $p r$ time series in detail without dividing into summer and winter precipitation. Daily average amount of precipitation which fell in those days when the measured $p r$ value was within the specified range is represented in Table 1. As is obvious from Fig. 1, daily precipitation amount in all reanalyses is, on average, overestimated in those days when $p r$ is below $2.5 \mathrm{~mm}$ (lines $1-5$ ) and underestimated when $p r$ is above $4 \mathrm{~mm}$ (lines 9, 10). Thus, the smoothing of $p r$ temporal distribution is characteristic of all the reanalyses: if (according to the measurements) the amount of fallen precipitation was less than a certain threshold value on any given day, then on the same day in the reanalyses $p r$ value is most likely to be overestimated, and vice versa. The mentioned threshold value falls within $2-2.5 \mathrm{~mm}$ range for the global reanalysis and $3.5-4.5 \mathrm{~mm}$ range for the regional reanalyses. It is interesting to point out that a similar phenomenon (but for the spatial distribution of daily precipitation amount only) was found in [14] when verifying other regional model RAMS (Regional Atmospheric Modeling System). The number of meteorological stations, the data of which was used by the author of study [14], was 5 times greater than the one in the given paper. But the author of [14] considered the modeling results for one day only, i.e. the model ability to forecast correctly a daily amount of precipitation fallen on a certain day over a large area was tested. According to his conclusions, RAMS model overestimated the daily precipitation amount at those stations where a small amount of precipitation fell, and vice versa.

T a ble 1

\section{Daily mean precipitation amount averaged over the stations on days when $p r$} (according to observational data) is within the given range

\begin{tabular}{|c|c|c|c|c|c|}
\hline \multirow{2}{*}{ № } & \multirow{2}{*}{$\begin{array}{c}\text { The range of } \\
\text { daily } \\
\text { precipitation } \\
\text { amount, } \\
\mathrm{mm} / \text { day }\end{array}$} & \multicolumn{4}{|c|}{$\begin{array}{l}\text { Precipitation amount } p r, \mathrm{~mm} / \text { day, according to the data } \\
\text { of }\end{array}$} \\
\hline & & $N E A C C$ & $M E R R A$ & PRECIS & $\operatorname{Reg} C M$ \\
\hline 1 & $0 \leq p r<0.5$ & 0.02 & 0.63 & 0.70 & 1.32 \\
\hline 2 & $0.5 \leq p r<1$ & 0.67 & 1.80 & 1.93 & 2.70 \\
\hline 3 & $1 \leq p r<1.5$ & 1.19 & 2.20 & 2.45 & 2.99 \\
\hline 4 & $1.5 \leq p r<2$ & 1.69 & 2.44 & 2.68 & 3.22 \\
\hline 5 & $2 \leq p r<2.5$ & 2.19 & 2.70 & 3.04 & 3.53 \\
\hline 6 & $2.5 \leq p r<3$ & 2.70 & 2.64 & 2.92 & 3.43 \\
\hline 7 & $3 \leq p r<3.5$ & 3.20 & 3.03 & 3.38 & 3.40 \\
\hline 8 & $3.5 \leq p r<4$ & 3.69 & 3.18 & 3.54 & 3.72 \\
\hline 9 & $4 \leq p r<4.5$ & 4.20 & 3.61 & 3.56 & 3.85 \\
\hline 10 & $4.5 \leq p r$ & 11.88 & 5.75 & 6.09 & 4.94 \\
\hline
\end{tabular}


It is obvious from Fig. 4 that in PRECIS and $\operatorname{RegCM}$ regional reanalyses the probability of detection of winter precipitation is higher than of the summer ones. In MERRA global reanalysis on the contrary: in winter $P O D$ is mainly smaller than in summer. The case is, as mentioned above, that the frequency of summer precipitation in MERRA is strongly overestimated and the more wet days are in the reanalysis, the more is a probability of event $N_{11}$ (see Formula 1). It is determined that there is a linear relationship between the precipitation frequency and probability of detection: correlation coefficients between freq and $P O D$ for all the reanalyses make up $0.7-0.9$.

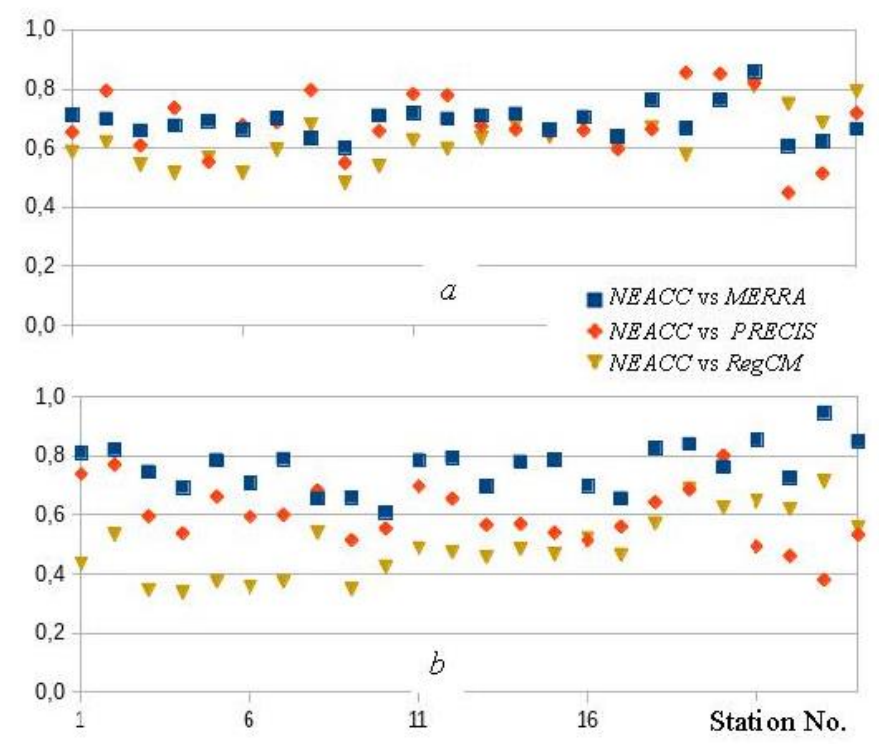

Fig. 4. Probability of detection $P O D$ at the stations in winter $(a)$ and in summer $(b)$

Now we are to consider the distribution functions of daily precipitation amount. Distribution functions calculated for winter and summer periods (using the relation (4)) and averaged over the number of meteorological stations are shown in Fig. 5. As is obvious from the figure, in winter the discrepancies between the measured and simulated values of $F^{*}(p r)$ function are significantly smaller than in summer. In winter root-mean-square error (which is a measure of discrepancy) is $2-3$ times smaller than in summer. The distribution function values constructed according to $\operatorname{Reg} C M$ reanalysis correlate best with the observational data.

One of rather informative characteristics of the distribution functions is the $95^{\text {th }}$ percentile $(P 95)$. The calculations reveal the fact that in winter P95 model values fit within $5-15 \mathrm{~mm}$ range at almost all the stations and correlate with observational data well. Significant discrepancies are observed only at the Caucasus coast, at the stations No. 20 and 21 situated in Sochi and Samtredia. In summer all the reanalyses are characterized by an underestimation of the $95^{\text {th }}$ percentile in comparison with the observational data. Thus, the aforementioned conclusion on the fact that summer extreme precipitation is underestimated in the reanalyses is confirmed. 

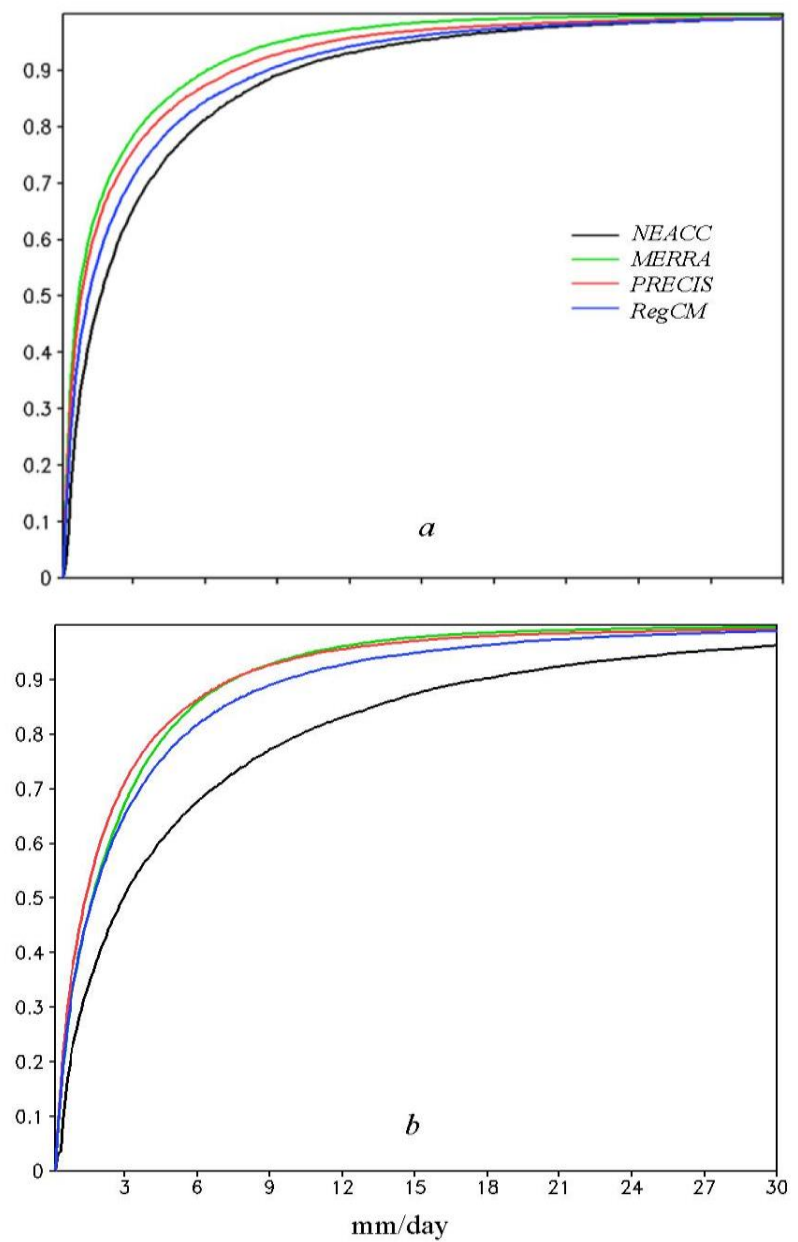

Fig. 5. Statistical distribution functions of daily precipitation amount $F^{*}(p r)$ in winter $(a)$ and in summer $(b)$

In view of interest to extreme precipitation we are to consider in more detail the data relating to Sochi where, according to $N E A C C$ data, precipitation intensity is the highest: $13 \mathrm{~mm}$ in winter and $18 \mathrm{~mm}$ in summer (see Fig. 1). First of all, it should be pointed out that the precipitation regime in Sochi is not typical for the coast of the mid-latitudes. Usually, in the seaside localities a bimodal annual course of precipitation with two maxima - summer and winter $[15,16]$ is observed. This can be observed, for instance, at the coastal stations in the Crimea (stations No. 8, 9 in Fig. 1). However, in Sochi a significant role in precipitation formation is played by an orography of the surrounding area, and the proximity of mountains is more important factor than the proximity of the sea. In the cold season Mediterranean cyclones that come from the West/South-West meet the Caucasian ridge on their way, and as a result of rise of warm and humid air masses precipitation falls on the windward slopes of the mountains. Therefore, the total amount of precipitation in Sochi in winter is $1.6-1.8$ times greater than in summer. So, the annual course of precipitation has a well-defined winter maximum. In summer the formation of cloudiness and precipitation is mainly due to the development of strong convection, 
therefore in summer the precipitation intensity and the $95^{\text {th }}$ percentile are greater than in winter. $P 95$ makes up 40 and $64 \mathrm{~mm}$ for winter and summer, respectively.

Gamma distribution of the function $F(p r)$ fitted to the observational data is denoted by a solid curve in Fig. 6. A double logarithm of distribution function is plotted on a horizontal axis, daily precipitation amount $(\mathrm{mm})$ - on a vertical axis. In Fig. 6 vertical line denotes the expected period that is equal to one year. The extreme precipitations (i.e. the amounts of precipitation that fall, on average, not more than 1 time per year) are situated to the right of the vertical line in Fig. 6.
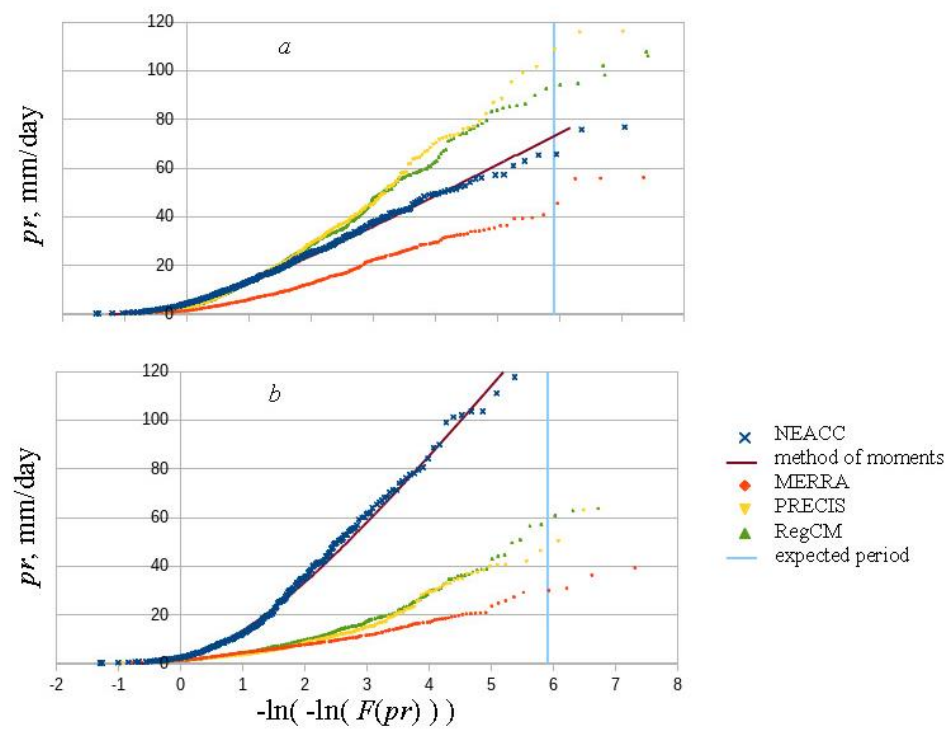

Fig. 6. The distribution function of daily precipitation amount in Sochi in winter $(a)$ and in summer (b). Solid line denotes gamma distribution.

According to Fig. 6, the forecasting of greater amount of precipitation (in comparison with MERRA) is characteristic of PRECIS and RegCM, and for the extreme precipitation the excess can reach $60 \mathrm{~mm}$. This is primarily due to the use of more coarse spatial resolution (the area of computational grid cell in MERRA is about 4.5 times bigger than in $\operatorname{Reg} C M$ and PRECIS) in the global reanalysis at which small-scale orographic heterogeneities of Caucasian coastal area are not taken into account. As a consequence, in comparison with the global model the values of the distribution function constructed according to regional models correlate with the observational data better (Fig. 6).

In winter precipitation amount in the regional models is strongly overestimated in comparison with the observation, whereas extreme precipitation amount in the regional reanalyses is $20-40 \mathrm{~mm}$ greater than according to measurement data (Fig. 6,a). This can be explained in the following way. Winter precipitation in the region of Sochi has mainly orographic origin: it appears due to the fact that the Mediterranean cyclones meet the Caucasus Mountains on their way. In the regional models coastal mountains overlap the sea, i.e. a non-zero height above the sea level is attributed to the "marine" points of computational grid located near the coast. This helps to avoid great differences in terrain altitude at the sea - land boundary and to provide numerical stability of the modeling. In this regard, the model height of terrain in the coastal area is, on average, $150-250 \mathrm{~m}$ higher than in reality. This results in the increase of forecasted precipitation amount on the windward slopes 
when humid air masses get over the orographic obstacle. In the global reanalysis winter precipitation amount is smaller than according to observational data as the height of the Caucasus Mountain Range is strongly underestimated in the model.

In summer (Fig. 6, b) precipitation amount is underestimated in both global and regional models in comparison with the observational data, although in $\operatorname{Reg} C M$ and PRECIS this underestimation is not as significant as in MERRA. Apparently, the cause of the underestimation is that the spatial resolution of the models is not sufficient for resolving an explicit convection and convective precipitation parameterization schemes applied in the models require improvement.

\section{Conclusion}

In general, the results of precipitation modeling in winter are in better agreement with observational data than in summer, as summer precipitation occurs mainly as a result of convection, and the horizontal scale of cumulus clouds is somewhat less than the spatial resolution of the reanalyses. The discrepancies between the modeling results and observational data are related mainly to the precipitation intensity underestimation and precipitation frequency overestimation. In summer the greatest intensity underestimation is characteristic of MERRA reanalysis and the smallest - of $\operatorname{Reg} C M$ reanalysis. The most overestimated winter precipitation frequency is in $\operatorname{Reg} C M$ reanalysis and it leads to the significant overestimation of total precipitation amount. In summer the most overestimated frequency is in MERRA reanalysis. In winter the forecasted precipitation distribution by the intensity in regional models correlates well with the actual one. Numerical indices are quite high according to both index of agreement and probability of detection. In summer the values of precipitation distribution function in all the models are strongly underestimated in comparison with the observational data.

It should be pointed out that all the reanalyses smooth the temporal precipitation distribution: in those days when less than $2 \mathrm{~mm}$ of precipitation fell, $p r$ is usually overestimated in the models, and in those days when more than $4 \mathrm{~mm}$ of precipitation fell it is underestimated.

Statistical distribution functions of daily precipitation amount constructed by the RegCM and PRECIS regional reanalyses correlate better with the observational data in comparison with $M E R R A$ global reanalysis. It is true both for distribution functions averaged over the number of meteorological stations and for a single meteorological station. As an example, a station located in a region with complex orography and intensive precipitation (Sochi) is considered. It is found that in winter in Sochi the precipitation amount in the regional reanalyses is strongly overestimated in comparison with the observational data, especially for extreme precipitations. It is concluded that this overestimation may be related to the features of terrain representation in RegCM and PRECIS. Fine spatial resolution in the regional models provides the representation of high mountains but this may result in the higher terrain altitude gradients if the mountains are situated near the sea - land boundary. An overestimated terrain height is attributed to computational grid points located in foothill region for providing numerical sustainability during the modeling. There is no need to use it in the global models as the mountain height is strongly smoothed due to rough spatial resolution.

Verification results of the reanalyses (considered in the paper) on the amount and the mere fact of precipitation event give us a reason to expect that in winter model precipitation of the RegCM and PRECIS reanalyses can be applied as an alternative to the observations in those regions where meteorological stations are absent, particularly in the water area of the Black Sea and the Sea of Azov. 
Annex. Geographical location of meteorological stations and relative number of the missed days

\begin{tabular}{|c|c|c|c|c|c|}
\hline No. & Town & $\begin{array}{c}\text { Longitude, } \\
{ }^{\circ} \mathrm{E}\end{array}$ & $\begin{array}{l}\text { Latitude, } \\
{ }^{\circ} \mathrm{N}\end{array}$ & $\begin{array}{c}\text { Meteorologi } \\
\text { cal site } \\
\text { altitude } \\
\text { above the } \\
\text { sea level, } \mathrm{m}\end{array}$ & $\begin{array}{c}\text { Relative number of } \\
\text { the missed winter and } \\
\text { summer days over } \\
1980 \text { - 2006 period, } \\
\%\end{array}$ \\
\hline 1 & Vinnytsia & 28.60 & 49.23 & 298 & 6 \\
\hline 2 & Chernivtsi & 25.90 & 48.37 & 246 & 7 \\
\hline 3 & Kishinev & 28.98 & 47.02 & 173 & 37 \\
\hline 4 & Odessa & 30.77 & 46.43 & 42 & 6 \\
\hline 5 & Izmail & 28.85 & 45.37 & 30 & 7 \\
\hline 6 & Genichesk & 34.82 & 46.17 & 15 & 7 \\
\hline 7 & Askania Nova & 33.88 & 46.45 & 30 & 7 \\
\hline 8 & Simferopol & 34.13 & 44.68 & 181 & 6 \\
\hline 9 & Feodosia & 35.38 & 45.03 & 26 & 7 \\
\hline 10 & Kerch & 36.42 & 45.40 & 49 & 6 \\
\hline 11 & Kharkiv & 36.13 & 49.97 & 155 & 6 \\
\hline 12 & Debaltsevo & 38.43 & 48.35 & 334 & 11 \\
\hline 13 & Tsymlyansk & 42.12 & 47.63 & 64 & 0 \\
\hline 14 & Rostov-on-Don & 39.82 & 47.25 & 88 & 15 \\
\hline 15 & Tselina & 41.05 & 46.55 & 111 & 21 \\
\hline 16 & $\begin{array}{c}\text { Primorsko- } \\
\text { Akhtarsk }\end{array}$ & 38.15 & 46.03 & 3 & 0 \\
\hline 17 & Elista & 44.33 & 46.37 & 151 & 0 \\
\hline 18 & Armavir & 41.12 & 44.98 & 158 & 0 \\
\hline 19 & Pyatigorsk & 43.03 & 44.05 & 533 & 38 \\
\hline 20 & Sochi & 39.77 & 43.58 & 57 & 4 \\
\hline 21 & Samtredia & 42.37 & 42.18 & 26 & 52 \\
\hline 22 & Tbilisi & 44.95 & 41.68 & 448 & 52 \\
\hline 23 & Leninakan/Gumri & 43.83 & 40.78 & 1512 & 56 \\
\hline 24 & Yerevan & 44.47 & 40.13 & 1140 & 55 \\
\hline
\end{tabular}




\section{REFERENCES}

1. Anisimov, A.E., Iarovaia, D.A. and Barabanov, V.S., 2015. Reanalysis of Atmospheric Circulation for the Black Sea-Caspian Region. Physical Oceanography, [e-journal] (4), pp. 13-25. doi:10.22449/1572-160X-2015-4-13-25

2. Iarovaia, D.A. and Efimov, V.V., 2016. Numerical Climatic Estimations of Precipitation and Surface Air Temperature for the Black Sea Region. Physical Oceanography, [e-journal] (3), pp. 57-69. doi:10.22449/1572-160X-2016-3-57-69

3. Elguindi, N., Bi, X., Giorgi, F., Nagarajan, B., Pal, J., Solmon, F., Rauscher, S., Zakey, A. and Giuliani, G., 2011. Regional Climatic Model RegCM User Manual. Version 4.3. Trieste, Italy: International Centre for Theoretical Physics, $32 \mathrm{p}$. Available at: https://gforge.ictp.it/gf/download/docmanfileversion/31/753/ReferenceMan.pdf [Accessed: 16 February 2016].

4. Rienecker, M.M., Suarez, M.J., Gelaro, R., Todling, R., Bacmeister, J., Liu, E., Bosilovich, M.G., Schubert, S.D. and Takacs, L. [et al.], 2011. MERRA: NASA's Modern-Era Retrospective Analysis for Research and Applications. J. Clim., [e-journal] 24(14), pp. 36243648. https://doi.org/10.1175/JCLI-D-11-00015.1

5. Anisimov, A.E. and Pososhkov, V.L., 2014. Otsenki Parametrov Atmosfernykh Osadkov v Chernomorskom Regione [Research of Noise at the Acoustic Time Quality Monitoring of Speed of the Stream]. In: A.B. Polonkiy ed., 2014. Sistemy Kontrolya Okruzhayushchey Sredy [Monitoring Systems of Environment]. Sevastopol: MHI. Vol. 20, pp. 132-135 (in Russian).

6. Dee, D.P., Uppala, S.M., Simmons, A.J., Berrisford, P., Poli, P., Kobayashi, S., Andrae, U., Balmaseda, M.A. and Balsamo, G. [et al.], 2011. The ERA-Interim Reanalysis: Configuration and Performance of the Data Assimilation System. Quart. J. Roy. Meteorol. Soc. [e-journal] 137(656), pp. 553-597, doi:10.1002/qj.828

7. WMO, 2002. Standardized Verification System (SVS) for Long-Range Forecasts (LRF). New Attachment II-9 to the Manual on the GDPS. Vol. 1. WMO-No. 485. Geneva: WMO, 24 p.

8. The North Eurasia Climate Centre. Download 223 Daily Station Series for the Territory of CIS. [online] Available at: http://neacc.meteoinfo.ru/monitoringdata/70-223-daily-downloads [Accessed: 16 February 2016].

9. European Climate Assessment \& Dataset. [online] Available at: http://eca.knmi.nl/ [Accessed: 16 February 2016].

10. Jones, R.G., Noguer, M., Hassell, D.C., Hudson, D., Wilson, S.S., Jenkins, G.J. and Mitchell, J.F.B., 2004. Generating High Resolution Climate Change Scenarios Using PRECIS. Exeter, UK: Met Office's Hadley Centre, 40 p.

11. Marzban, C. and Stumpf, G.J., 1998. A Neural Network for Damaging wind Prediction. Weather and Forecasting, [e-journal] 13(1), pp. 151-163. Available at: http://journals.ametsoc.org/doi/full/10.1175/1520-

0434\%281998\%29013\%3C0151\%3AANNFDW\%3E2.0.CO\%3B2 [Accessed: 2 February 2016].

12. Willmott, C.J., 1982. Some Comments on the Evaluation of Model Performance. Bull. Amer. Meteor. Soc., [e-journal] 63(11), pp. 1309-1313. doi:10.1175/15200477(1982)063<1309:SCOTEO>2.0.CO;2

13. Wilks, D.S., 1995. Statistical Methods in the Atmospheric Sciences: An Introduction. SanDiego: Academic Press, 464 p. doi:10.1016/S0074-6142(06)80036-7

14. Schultz, P., 1995. An Explicit Cloud Physics Parametrization for Operational Numerical Weather Prediction. Mon. Wea. Rev., [e-journal] 123(11), pp. 3331-3343. doi:10.1175/15200493(1995)123<3331:AECPPF>2.0.CO;2

15. Lipinskiy, V.M., Dyachuk, V.A. and Babichenko, V.N. eds., 2003. Klimat Ukrainy [The Climate of Ukraine]. Kiev: Izd-vo Raevskogo, 343 p. (in Russian).

16. Efimov, V.V., Shakalova, E.S. and Gubanova, E.V., 2006. Otsenka Izmeneniya Ekstremal'nykh Osadkov Chernomorskogo Regiona v XX Stoletii [Estimation of Extreme Precipitation Variation in the 20th Century for the Black Sea Region]. Morskoy Gidrofizicheskiy Zhurnal, (6), pp. 73-77 (in Russian). 